laps, swathed them carefully in wrappings of cloth selected by the mother from her most valued treasures, repeated above them a short prayer, and, stealing out unobserved, dug a suitable pit and buried them in it.

The night after the return of the Pokegemas with the Sioux bodies, they treated themselves to a great feast at the island, which culminated in the usual hideous orgies. From this banquet the better class of the band absented themselves. Sioux flesh was at this time boiled and eaten with wild rice. Mrs. Ayer, testifying absolutely to this latter point, adds, that the given instance of cannibalism is the only one coming to her personal knowledge during the whole period of her connection with the wild Ojibwas, something more than twenty years.

We-zhai-ma, who had been mourned as a victim of the Sioux. re appeared after the attack on Lake Pokegema. He had managed to elude pursuit while the enemy were busied with their captive, and had finally succeeded in effecting escape. When lie eventually resumed his return, it was by a circuitous route which materially delayed his arrival at home.

The events here detailed sealed the fate of the Pokegemas as an independent band. Constant dread of Sioux incursions caused these people to abandon their hunting and fishing grounds at the lake, and betake themselves to regions less accessible to the foe. They melted away from Pokegema as if by magic, withdrawing singly and in groups, and retiring for the most part to the north and north-west; many of them fleeing to Mille Lacs and Lake Superior. Within a very short time they were wholly absorbed in cognate branches of the great Ojibwa tribe, presenting a case of the complete disintegration of an aboriginal community without corresponding loss.

Coldwater, Mich., June 4

Franc E. Babbitr.

\section{The agricultural experiment-station of New Jersey.}

For a state so peculiarly located with reference to market facilities as New Jersey, and containing, withal, such large areas of unproductive soil, it would seem most appropriate that the study of artificial sources of soil-fertility should constitute, as it does in that state, the primary work of the state agricultural experiment-station.

There are certain features of the work of this New Jersey station, as detailed in its recent reports, to which I wish briefly to direct attention. One of these is, that, with but trifling exceptions, the entire resources of the station are directed to the solution of the chosen problem, and that no attempt is made to skim over the limitless field of agricultural research.

Another notable feature is that the field and feeding experiments, all of which bear directly or indirectly upon the central problem under investigation, are conducted upon the parallel lines of laboratory analysis accompanied by field or stable tests; the fact having apparently been recognized that the chemist's analysis alone is not a sufficient criterion upon which to base an estimate of the agricultural value of a fertilizer or feeding-stuff, although an essential factor in forming that estimate.

A third conspicuous feature of the work of this station is the absence of that class of experiments which can justly be styled 'empirical.' The field-experiments especially are co-ordinated upon a thoroughly scientific plan, and constitute a form of research which requires for its successful prosecution as high a degree of scientific ability as is ever called for in the chemist's or physiologist's laboratory.

The institution of duplicate experiments on farms in various parts of the state is another commendable feature of this station's work. in that it not only brings under observation the effects of differences in soil and climate, but is educating a number of farmers in the methods of accurate experimentation.

No doubt there are many citizens of New Jersey who feel that their special interests are being neglected by the state experiment station; but I believe that the station is doing wisely in confining its work to such questions of primary importance as may be thoroughly handled. To do a definite work well is far better than to skim over a larger field, especially in science, where half-truths are so liable to be whole errors ; and I believe that its present course will the sooner bring to this station the means for enlarging its field of useful work.

\section{E. Thorne.}

\section{Penetrating-power of arrows.}

Some time since, I noticed a letter in Science asking for information in regard to the penetrating-force of the arrow.

I have in my possession the sixth dorsal vertebra of a buffalo, the spine of which contains an iron arrow-point. The arrow struck the spine about two inches above the centre of the spinal canal, and penetrated the bone .82 of an inch. The bone at the point struck is .55 of an inch thick, and the point of the arrow protrudes beyond the bone .27 of an inch. The arrow was shot from the right side of the animal, and the plane of the point was horizontal. The animal was mature, and the bones well ossified. Though the vertebra has been much weathered, the epiphyses adhere closely. The animal was not as large as some individuals. The whole vertical length of the vertebra is thirteen inches.

The arrow must have penetrated several inches of flesh before striking the bone. Olrver MARCY.

North-western university, Evanston, Ill., May 31.

\section{Spectrum of comet c. $\mathbf{1} 886$.}

Comet c. 1886 presents to telescopic vision a rather bright oval of light, with an ill-defined nucleus in the north preceding quadrant. Although a faint object, it was so temptingly situated for observation, that, rather out of curiosity, the telescope, already employed in faint spectroscopic work, was directed upon it. The method of observation, while adapted to use very faint light, is yet supplied with checks against optical illusion. Observations were obtained on May 26, 28, and June 4. They afford five loci of light, agreeing fairly in position with the five series of lines in the low-temperature spectrum of carbohydrogen, and afford a strong suspicion of other loci, two of which lie near strong lines in the low-temperature spectrum of oxygen, and others to the lowtemperature spectrum of carbo-oxygen. The spectra given in micrometric gaseous spectra by Piazzi Smyth have in each case been used as reference.

New Haven, Conn., June 8.
O. T. S. 